\title{
Exploration and Application of PBGS Teaching Mode to Management Courses
}

\author{
Hui Jin \\ School of Economic Management, Yanbian University, Yanji, 133002, China
}

Keywords: PBGS teaching mode. Management course. Talent cultivation

\begin{abstract}
To look for more scientific and more efficient teaching methods and modes, all universities and colleges continuously explore teaching methods of management courses and carry out innovation. Successful application of PBGS teaching mode not only improves teaching quality and teaching effectiveness for universities and colleges further but also has promoting effect on students' development in all aspects based on this, such as knowledge, ability and quality, and absolutely support students' adaptive capacity in future society. This thesis analyzes and compares drawbacks of teaching methods related to management subjects at universities and colleges and advantages of PBGS teaching mode. Meanwhile, it takes the combination between PBGS mode and practical teaching of the course 'Entrepreneurial Management' at Business College, Nankai University as an example to explore how entrepreneurial talent can be cultivated by PBGS teaching mode.
\end{abstract}

\section{Introduction}

As main teaching content of all universities and colleges, the subject Business Administration mainly takes large-scale class teaching as its teaching mode and still follows traditional educational mode, i.e. 'duck-stuffing'. This teaching method largely hinders students' development in many aspects, such as independent thinking, innovation, practice and collaboration ability. PBGS mode establishes stiff teaching methods about teaching materials in complicated projects with practicalness and makes students solve authentic problems by team work so that they can learn scientific knowledge behind problems. This is of positive significance for students' improvement in the aspects of thinking, problem-solving and independent learning.

\section{Analysis of PBGS teaching mode}

\section{Analysis of connotation}

PBGS (Project Based Group Study) is team learning based on projects. Specific analysis of this teaching mode mainly involves content of two aspects, i.e., projects and teams. The said project means all related problems are integrated effectively according to demands of goals, mutual resource sharing is realized, and relevant support based on products and service are made eventually. The said teams refer to integrated groups with common goals, specific working methods and some constraining force in implementation. According to this, main carrier of this teaching mod is the teaching schemes which are formed finally by projects, which teaching takes charge of, with the help of mutual communication and cooperation in the whole team.

\section{Analysis of features}

Compared with traditional acceptance-type learning method, PBGS has its own features, i.e., it pays attention to situations of students' cultivation in the aspects of consciousness of problems, teamwork, critical thinking and independent ability. It successfully transits the three elements in traditional teaching, i.e., teacher, book and students, to four elements, i.e., teaching situation, teaching item, teaching group and teacher giving lesson. In the four elements, teaching item and classroom teaching situation are keys to the whole course. At this moment, teaching group mainly aims at finishing the whole teaching item and the teaching giving lessons becomes collaborators and instructors of students. This teaching mode makes students become the first subject with constitutive 
property in teaching activities so that students can jump out of stiff and boring teaching materials and the whole learning process has more flexibility, situationality and practicalness.

\section{Features of the course 'Entrepreneurial Management' and its integrating point with PBGS teaching mode}

\section{Features of the course 'Entrepreneurial Management'}

According to long-term investigation and researches of domestic and foreign colleges and many authoritative organizations on actual demands and development situations of domestic and foreign market and all kinds of enterprises at present, Business College of Nankai University succeeded in establishing the course 'Entrepreneurial Management' by combining with comprehensive consideration on students' ability and quality cultivation in all aspects and according to actual situations about development of domestic entrepreneurial management education in 2008. Main content of the course 'Entrepreneurial Management' lays particular stress on intensifying overall framework of 'opinions, knowledge, skills and actions' and centers on practical training of entrepreneurial process. For this, in addition to special column and cited examples, teaching material column of the course 'Entrepreneurial Management' also establishes content like key concepts, survey data, entrepreneurs' conversation on pioneering work, study and reading on literature, action guidance and extracurricular exercise. When it pays attention to strengthening key elements, it also combines key elements with the process of entrepreneurial activities closely.

\section{Integrating point between the course 'Entrepreneurial Management' and PBGS teaching mode}

Since teaching process of the course 'Entrepreneurial Management' is realized in the form that combines problems with cases and content of the course lay particular emphasis on cultivating students' self-employed thinking, cognition and ability and improving students' subjective initiative, independent thinking and ability to solve problems. Compared with courses taking traditional modes, the course 'Entrepreneurial Management' have had significant breakthrough and innovative attempt in both teaching material design and teaching method, which makes the whole teaching process approach practical life to a larger extent and has stronger practicability and flexibility. All of these features have many similarities with characteristics of PBGS teaching mode. In practical teaching, teachers from College of Nankai Universities accelerate realization of established purport of the course 'Entrepreneurial Management' and implementation of new teaching modes largely by combining PBGS teaching mode with teaching process of the course 'Entrepreneurial Management' imperceptibly and effectively.

\section{Specific application of PBGS teaching mode to the teaching process of the course 'Entrepreneurial Management'}

\section{Teaching process of PBGS teaching mode}

Teaching process of PBGS teaching mode mainly involves several aspects, i.e., designing project, organizing groups, project approval, project development, communication, studying achievements and final conclusion. Teachings thoughts of management subjects based on PBGS: firstly, teachers bring students to large environment of the course by explanation and then guide students into specific researches of projects step by step. Students in the whole class study different themes in groups and by intra-group cooperation and inter-group competition. At last, all groups finish learning of the whole course by achievement exhibition, communication and evaluation.

Teaching system of the course 'Entrepreneurial Management' based on PBGS mode

The teaching framework of the course 'Entrepreneurial Management' based on PBGS mode at Business College of Nankai University is mainly composed of three basic modules. Specifically, they include:

Firstly, basic knowledge about pioneering work. Its project setting contains: 
Sub-project setting: learn essence and features of entrepreneurial activities, conventional operational process, situations generated in process of activities, numerous factors affecting pioneering work (environmental factor and human factor), as well as comprehensive case analysis + sub-projects of practical assignment.

Secondly, entrepreneurial activities. Its project setting contains:

1). Decide to be entrepreneurs and analyze specific setting of its sub-projects: analyzing entrepreneurs' entrepreneurial motivation and their impacts on entrepreneurial activities; analyze entrepreneurs' unique skills and quality, recognize rational factors of entrepreneurial activities in entrepreneurial myth; and carry out comprehensive case analysis + sub-projects of practical assignment.

2). Recognize and evaluate entrepreneurial opportunities. Its sub-project setting contains: mater opportunity identification and judge basic methods; grasp and judge features of chances that are appropriate for individual entrepreneurs, learn purposes and methods of evaluation on entrepreneurial opportunities, promote approaches of opportunity recognition capability, study main techniques generated by pioneering work, and carry out comprehensive case analysis + sub-projects of practical assignment.

3). Develop business models. Its sub-project setting contains: learn connotation and peculiarity of business models, comprehend logicality of business models, know design of business models, and carry out comprehensive case analysis + sub-projects of practical assignment.

4). Build splendid entrepreneur teams. Its sub-project setting contains: learn importance of entrepreneur teams for venture success, comprehend main problems that team establishment must consider, know general laws of entrepreneur teams' evolution and realize standards of entrepreneur teams, and carry out comprehensive case analysis + sub-projects of practical assignment.

Secondly, correlation among pioneering work, society and individual. Its project setting contains:

1). Corporate entrepreneurship. Its sub-project setting contains: learn background of companies' entrepreneurial practice, understand effect of entrepreneurship and skills on adaptation to social development and improvement in competitive edges, compare differences and similarities between entrepreneurial management and traditional management, and carry out comprehensive case analysis + sub-projects of practical assignment.

2). Universality of pioneering work and career development. Its sub-project setting contains: implement system review and draw conclusions on the whole textbook content, master essence of entrepreneurship and skills, comprehend effect of entrepreneurship and skills on individuals' career development, and carry out comprehensive case analysis + sub-projects of practical assignment.

\section{Feedback about teaching achievements of the course 'Entrepreneurial Management' based on PBGS mode, problems and improving countermeasures}

\section{Feedback about teaching achievements of the course 'Entrepreneurial Management' based on PBGS mode}

Overall, benign combination of PBGS teaching mode and the course 'Entrepreneurial Management' is welcomed by most students and also arouses students' enthusiasm for self-expression and continuous innovation. As a result, classroom climate is extremely active and students' reaction is relatively intense. Via investigation, it can be summarized as the following aspects specifically:

First of all, carry out outdoor training on life pattern for students. As teachers, they should establish their questions reasonably, such as students' plans about self-employment after graduation, the reason why they choose self-employment and analysis of the reason why they do not consider self-employment. Self-employment is rarely included in scope of students' consideration because there are two career plans in traditional thinking of most students entering key universities, i.e., they want to enter famous large-scale enterprises to get their own positions or they will compete with numerous people to pass a single-plank bridge (working hard to pass the examination and be a civil 
servant). In the first lesson, teachers propose questions related to career planning. After collision of different opinions, more students feel achievements obtained by passion should be a meaningful thing.

Secondly, rebuild thinking mode. In our traditional educational constitution and system, all universities and colleges have slogans and principles that they have followed all the time at different stages of education, i.e., cultivating students' innovative consciousness. However, teaching work that can be applied practically is little. At last, the slogan becomes an empty talk in a superficial form. In management classroom, teachers encourage students to answer questions based on many aspects to make students think about things. According to this, some ideas of teachers is largely open for students, which arouses students' enthusiasm to do something unconventional to a large extent. In the first assignment, teachers assign assignments related to product development consciously and give sufficient time to students to think, collect information in many aspects, form their own opinions and evaluation eventually and perform mutual sharing and communication in classroom.

Next, rethink about application of management. For teachers, they use facts that they contact with in practical life as examples in classroom to ensure teaching effect. It is obvious that this teaching method can not only show practical application value of management sufficiently but also develop students' ability to discover and explore surrounding things further.

Finally, re-cognition of ego. For entrepreneurs, the largest resource is themselves. With teachers' guidance, students begin to think about what resources they have owned up to now, which resources are needed, which resources they can possess by their potential and which resources that surrounding people have and are worth integrating.

\section{Problems in teaching of the course 'Entrepreneurial Management' based on PBGS mode and improving countermeasures}

Firstly, the problem that there is difference in students' ability and the degree to which they master knowledge. Since students have difference in personal ability and mastery of professional foundation, the teaching of the course 'Entrepreneurial Management' under PBGS mode shows many possibilities and gaps. Undoubtedly, this will trigger a chaotic situation between progress and effect. Hence, this requires that teachers should give full play to coordinating and leading roles in the process in which students finish projects in groups or assignments are operated specifically, and teach students by personal examples as well as verbal instruction. When teachers divide students into groups, they should pay attention to interests of the whole. On the other hand, they must consider difference among different students, and deploy students with different ability and various degrees of advantages reasonably and evenly by adjusting members of each group slightly, which can not only help students exert their own advantages in project activities of assignments actively and effectively but also accelerate students' mutual learning and cooperation largely.

Secondly, the problem about requirements for teachers' own ability. The teaching of the course 'Entrepreneurial Management' based on PBGS mode puts forward high requirements for teachers' personal quality and ability, and acts as a new challenge that educational pattern in new era proposes for teachers. It is required that teachers should spend more time on preparation before giving lessons and give more sufficient and all-round consideration to course content. While giving lessons, they should not only have more systematic teaching thoughts but also need splendid strain capacity, opener and more flexible thinking and creativity, and master degree of correlation among courses. When teachers divide students into groups to finish assignment projects, they should implement global guidance and coordination, combine with students' own practical situations to give specific guidance and design a teaching scheme that can really adapt to different students' future development eventually.

\section{Conclusion}

To sum up, PBGS is an inquiry and task-driven teaching method and learning mode, which emphasizes effect of teams to a larger extent. When this teaching mode is successfully used to cultivate students' practical ability, it also injects new vitality into improvement in teaching quality of 
management subjects at universities and colleges. At the same time, it will provide food reference and promotion for teaching reform and innovation.

\section{References}

[1] Yang Huiying. Primary Exploration on Teaching Evaluation System of Economic Management Courses based on PBGS Teaching Mode, Economic Research Journal, 2012 (14).

[2] Lei Kewei and Liu Xiaoli. Exploration and Application of PBGS Teaching Mode to Teaching of the Major Tourism Management - Taking Introduction to Tourism as Example, Science \& Technology Information, 2010(9).

[3] Luo Congyan. Comparison between PBGS Mode Based on Accounting Manual Simulation Training and Traditional Mode, Science \& Technology Information, 2009.

[4] Yang Huiying. A Research on Application of Teaching Mode of 'the Project-based Group Learning’ - For Economic Management Courses, Northern Economy and Trade, 2012(05).

[5] Li Weixiu. Exploration and Application of PBGS Teaching Mode to Higher Technical and Vocational Education - Take Operation Management of Travel Agencies as An example, Journal of Taiyuan Urban Vocational College, 2008(05).

[6] Wu Xianwen and Chen Chenghuan. Exploration and Application of 'Project-driven + Case Teaching' to Higher Technical and Vocational Education, Computer Knowledge and Technology (Academic Communication), 2007(06).

[7] Zhao Haifeng. Cultivation of Comprehensive Ability and PBGS Teaching mode [J]. Master, 2011(16). 